\title{
Marssonina leaf spot of poplar in Finland
}

\author{
WEI HE and TIMO KURKELA
}

\begin{abstract}
HE, W. \& KURKELA, T. 1989: Marssonina leaf spot of poplar in Finland. - Karstenia 28:87-92.

The host range of Marssonina populi and $M$. castagnei, and the relative susceptibility of various poplars to these fungi, were determined through laboratory inoculation tests and a field study. Nine species or hybrids of Populus in sect. Aigeiros and Tacamahaca were found susceptible to $M$. populi, and five species or hybrids in section Populus (Leuce) proved to be susceptible to $M$. castagnei. The life cycle of $M$. populi was also studied. $M$. castagnei was recorded for the first time in Finland.
\end{abstract}

Wei He, Department of Forestry, Beijing Forestry University, Beijing, China Timo Kurkela, The Finnish Forest Research Institute, Department of Forest Protection, P.O. Box 18, SF-01301 Vantaa, Finland

\section{Introduction}

Marssonina leaf spot of poplar (Populus spp.) has been reported from all the most important areas of poplar cultivation in Europe, America, Asia and New Zealand (Anonymous 1981). In Scandinavia, Marssonina populi (Lib.) Magnus has been found in Denmark, Norway, Sweden and Finland (Buchwald et al. 1961). M. castagnei (Desm. \& Mont.) Magnus, $M$. tremulae (Lib.) Kleb. and M. tremuloides Kleb. have been found in Norway (Semb \& HirvonenSemb 1964). Spiers (1984) mentions M. brunnea (Ell. \& Ev.) Magnus and M. castagnei found in Norway and Sweden. The teleomorphs of these coelomycetes are known to belong to the discomycete genus Drepanopeziza (e.g. Rimpau 1962). In Finland, only a few specimens of $M$. populi on some poplar species have been preserved in the herbarium of the Finnish Forest Research Institute (HFR). The species of the pathogens, and their host range and life cycle on poplars have not been studied more closely in Finland. The aim of this study was to investigate these aspects.

\section{Materials and methods}

Plant material for inoculation

Cuttings of various poplar species were taken from one-year-old wood seedlings in the nursery of the Finnish Forest Research Institute (FFRI) in March,
1987 , and planted in pots in a greenhouse. The rooted cuttings (plants) were prepared for inoculation tests. Leaves from different poplar species were picked for leaf-disc inoculation from the FFRI nursery or parks in Helsinki.

\section{Inoculation with ascospores}

\section{a. Ripening of apothecia}

Fallen leaves of Populus $\mathrm{x}$ rasumowskiana (Regel) Dippel with an abundance of small apothecia were collected in Tikkurila, Vantaa, at the end of April 1987. The leaves were placed outdoors and kept in a net-covered plastic box, out of direct sunlight. They were checked regularly for the ripening of apothecia. One hundred asci from 30 apothecia were randomly selected for each sample, and the percentage of asci with spores was counted.

\section{b. Inoculation with ascospores}

Inoculations were made in June, after laboratory confirmation of the discharge of ascospores. Leaf fragments bearing mature apothecia of the Drepanopeziza stage were attached to the inside of a petri-dish cover, and placed over a dish containing $2 \mathrm{~cm}$ diameter poplar leaf discs laid into holes punched in $2 \%$ water agar. The upper as well as the underside of the leafdiscs were exposed to ascospore discharge. Three 
poplar species were chosen for pathogenicity tests. For each species, 12 discs were inoculated, 6 adaxially and 6 abaxially.

\section{Host range and pathogenicity tests}

The agar leaf-discs technique (Spiers 1978) was used for testing the host range and pathogenicity of Marssonina species. Leaf discs were punched from matured leaves. Conidia for inoculation were scraped from the diseased leaf-discs inoculated with ascospores. A suspension of conidia was made with distilled water, and the conidial concentration was assessed with a Bürker hemacytometer. Each leaf-disc was inoculated with $0.15 \mathrm{ml}$ of the suspension, containing 5000 conidia. After inoculation, the plates were incubated in a chamber for 30 days under the following conditions: $20^{\circ} \mathrm{C}, 17 \mathrm{~h}$ light $/ 13^{\circ} \mathrm{C}, 7 \mathrm{~h}$ dark. For each species, cultivar, and hybrid, 16 discs were inoculated, 8 adaxially, 8 abaxially.

Disease severity was assessed after 20 days of incubation by counting the number of lesions $/ \mathrm{cm}^{2}$ of leaf area with a binocular microscope, using the scale proposed by Spiers (1978) with minor modifications (Table 1).

\section{Field study}

The field study was carried out from May to September, 1987 in the Helsinki area and the FFRI nursery in Vantaa, southern Finland. Five disease classes (Table 1) were used for indicating the level of infection, based on the number of lesions per $\mathrm{cm}^{2}$ of leaf area.

\section{Observation of disease development}

A growth chamber was employed for the plant inoculation test. The temperature, relative humidity and illumination were controlled by a computer program designated to provide favorable conditions for the development of the disease. The intensity of the illumination varied from 10000 to 50000 lux according to the distance of plants from the light source and the hours of illumination. Maximum intensity was programed for between 12:00 and 15:00 hours (Fig. 1). A random selection of 10 plants of $P . \times$ rasumowskiana (Regel) Dippel was made, and 8 mature leaves on each plant were inoculated. A conidial suspension of $M$. populi was prepared from acervuli on the diseased leaves of $P$. $\times$ rasumowskiana, picked from the FFRI nursery. The adaxial surface of each leaf was smeared with $0.2 \mathrm{ml}$ of this suspension, containing $10^{5}$ conidia. The inoculum per unit of leaf area was

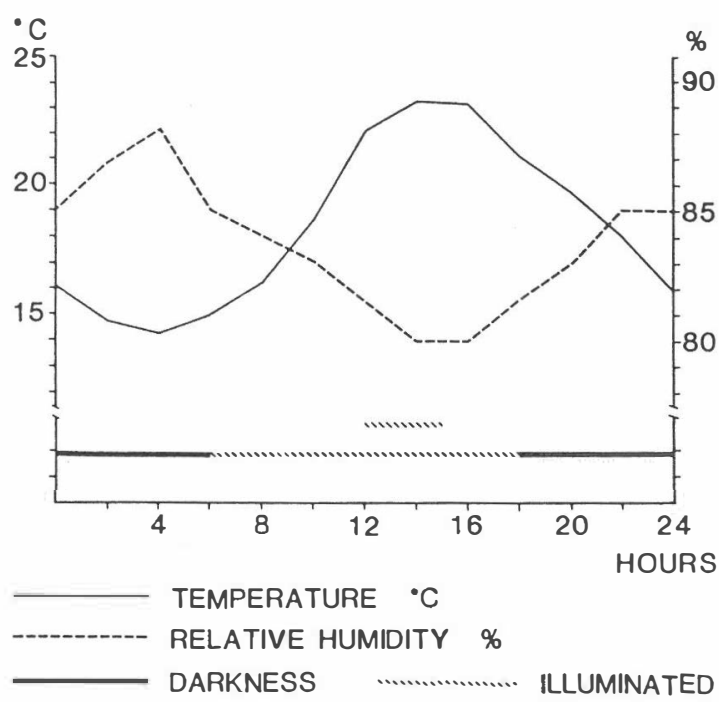

Fig. 1. The temperature, relative humidity, and illumination conditions in the growth chamber, in 24 hour cycles from 15 August to 15 September, 1987.

roughly the same as in the leaf-disc inoculations mentioned above. After inoculation, the plants were covered with plastic bags for 24 hours. Five plants served as controls. The plants were kept in the chamber for one month. The same infection classes (Table 1) were used for scoring the infection level.

\section{Results}

Measurement and identification of the pathogens

On the basis of conidial morphology (shape, mean dimension and septum location), the fungus on $P . \times$ rasumowskiana described below was identified as $M$. populi. The apothecia, of its perfect stage, represent Drepanopeziza populorum (Desm.) Höhnel. The fungus on $P$. alba $\mathrm{L}$. proved to be $M$. castagnei.

Apothecia on the overwintered leaves of $P . \times$ rasumowskiana were $150-380 \mu \mathrm{m}$ in diameter, the excipulum 13-33 $\mu \mathrm{m}$, and the asci 70-125 x 12-20 $\mu \mathrm{m}$ and club-shaped (Fig. 2). The ascospores were $14.5-19 \times 6-8.5 \mu \mathrm{m}$. Acervuli on the newly infected leaves of same host, collected in the field, were 130$325 \mu \mathrm{m}$ in diameter, conidia $16.5-24 \times 8.5-12 \mu \mathrm{m}$, and the average length of the smaller cells of the conidia was $28 \%$ of average total length (Fig. 3).

Acervuli of $M$. castagnei on the newly infected leaves of $P$. alba 'Nivea', collected in the field, were 
Table 1. Disease class scale and susceptibility classification for assessing poplars for resistance to Marssonina species in laboratory inoculations.

\begin{tabular}{ccll}
\hline Disease class & $\begin{array}{c}\text { Number of lesions/ } \\
\mathrm{cm}^{2} \text { leaf area }\end{array}$ & Infection level & \multicolumn{1}{c}{$\begin{array}{l}\text { Susceptibility } \\
\text { classification }\end{array}$} \\
\hline 0 & 0 & nil & highly resistant \\
1 & $1-10$ & light & resistant \\
2 & $10-25$ & medium & susceptible \\
3 & 25 , discrete & heavy & very susceptible \\
4 & coalesced & heavy & very susceptible \\
\hline
\end{tabular}

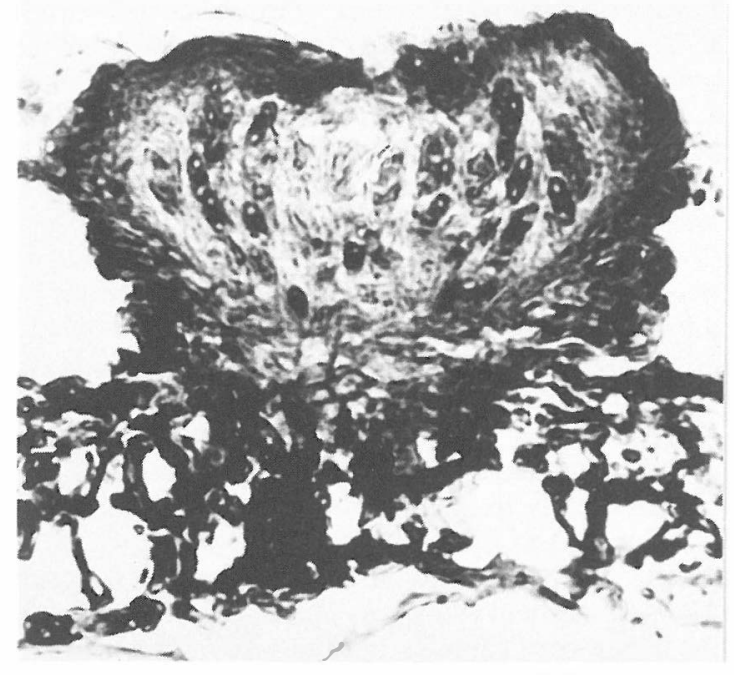

Fig. 2. Cross section of an apothecium of Drepanopeziza populorum, $\times 280$.

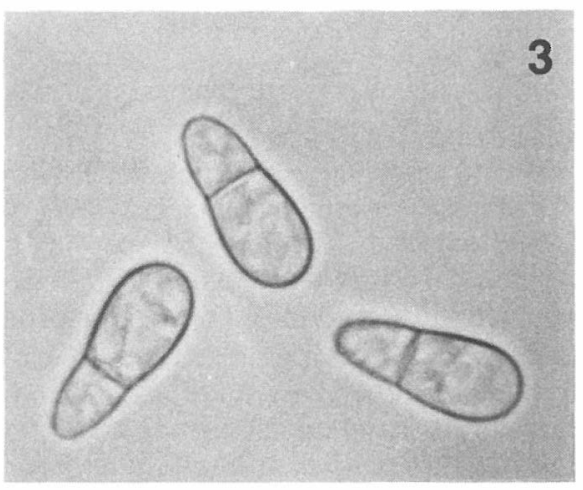

$150-480 \mu \mathrm{m}$ in diameter, conidia $16-24 \times 6.5-$ $9.5 \mu \mathrm{m}$, and the average length of the smaller cells of the conidia was $40 \%$ of average total length (Fig. 4).

\section{Fungal isolates and cultures}

Single ascospore isolates of $D$. populorum from the overwintered leaves of $P . \times$ rasumowskiana, and leaf tissue isolates of $M$. castagnei from the leaves of $P$. alba 'Nivea', were made and cultured on malt agar plates, and incubated under the same chamber conditions as for the leaf-disc inoculations mentioned above. After one and half months, conidial pustules containing $17-27 \times 5-10 \mu \mathrm{m}$ conidia developed in the former cultures. After 20 days, conidia measuring 16-22 × 6-13 $\mu \mathrm{m}$ formed on the latter cultures. Inoculation of plants of $P . \times$ rasumowskiana with a conidial suspension of $M$. populi confirmed its pathogenicity.

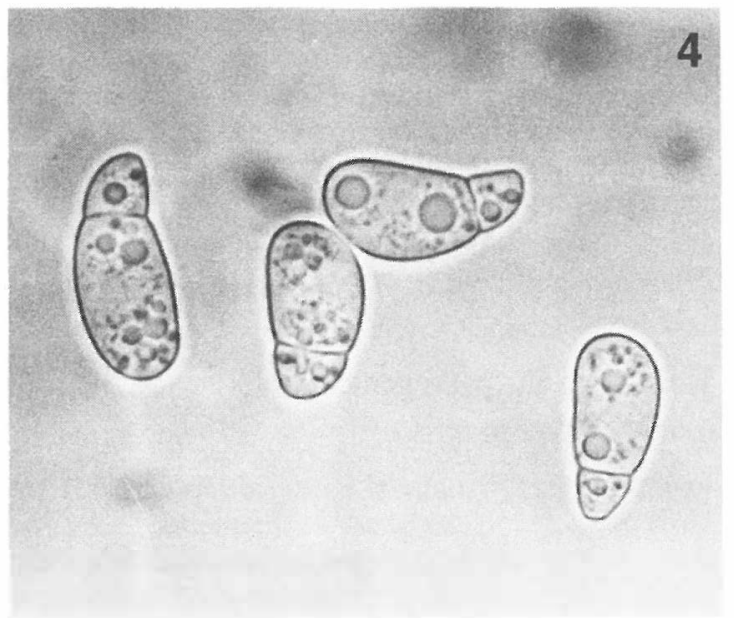

Figs. 3-4. - Fig. 3: Conidia of Marssonina populi, $\times 1000$. - Fig. 4: Conidia of Marssonina castagnei, x 1000. 


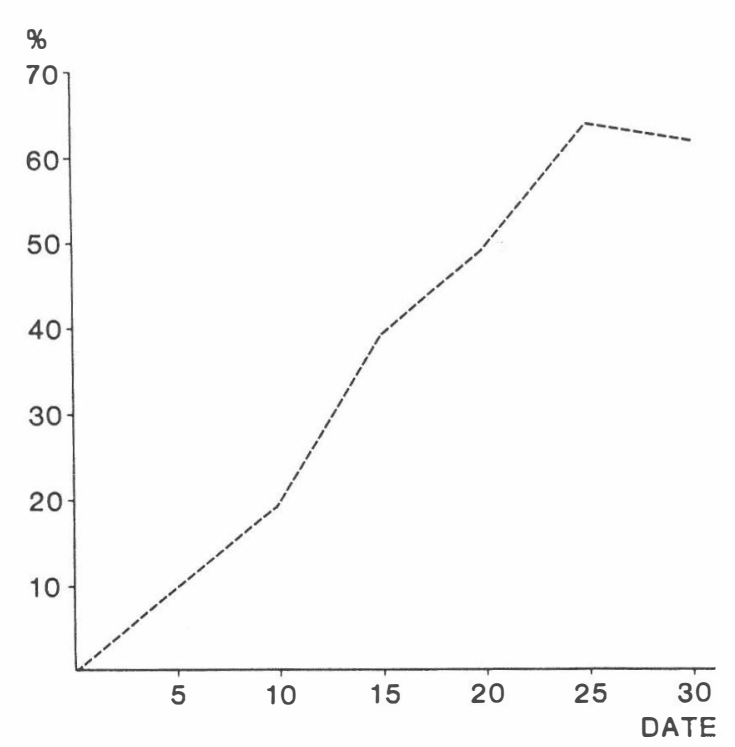

Fig. 5. Ripening of the apothecia of Drepanopeziza populorum in the field during May (1987), expressed as the percentage of asci with ascospores in relation to time.

\section{Life cycle of Drepanopeziza populorum}

Ascospores of $D$. populorum formed at the beginning of May. When the percentage of ascus with spores reached about $65 \%$, ascospore discharge could be easily set off; the apothecia ripened during this time (Fig. 5).

In the petri plates, typical spots with acervuli containing $16-25 \times 8-10.5 \mu \mathrm{m}$ conidia were produced on the leaf-disc of $P$. nigra at 9 days from inoculation. $P$. $\times$ rasumowskiana was also susceptible. The percentage of infected leaf-discs was $100 \%$, and both sides of the leaf-disc were infected. All the controls and $P$. tremula remained free from infections. This indicates that a definite relation exists between $D$. populorum and $M$. populi that they are stages of the same fungus species.

\section{Host range and pathogenicity tests}

\section{a. Inoculation tests}

In the section Populus (Leuce), all species and hybrids were highly resistant. In the section Aigeiros, $P$. nigra was highly susceptible. In the section Tacamahaca, $P$. balsamifera 'Elongata' and $P$. balsamifera L. X trichocarpa Torr. \& A. Gray ex Hook. were resistant whereas $P$. $\times$ rasumowskiana was highly susceptible, and the others in this section were also infected. There was also marked difference between the susceptibility of leaf surfaces; less infection was recorded on the adaxial than on the abaxial surface of leaf-discs of the above species, hybrids, or cultivars. In the hybrids of the Populus sections Tacamahaca and Aigeiros, the same tendency was observed (Table 2).

\section{b. Field study}

In the Helsinki area, the initial symptoms of infection appeared on the leaves of $P . \times$ rasumowskiana in early June. The primary infection caused deformation of the tender, expanding leaves. Marssonina lesions formed on the abaxial surface of most infected leaves. It was presumed that the inoculum came from the overwintered leaves with apothecia, from which ascospore discharge began during the last week of May, according to the laboratory ascospore inoculation experiment. Symptoms which appeared on the leaf blade of susceptible species, were typical dendritic lesions; those on resistant species consisted of smaller, circular to angular, black lesions. Lesions on the petioles and on young shoots were observed only on the most susceptible species: $P . \times$ rasumowskiana and $P$. nigra $\mathrm{L}$.

The infected leaves of $P . \times$ rasumowskiana began to fall prematurely in mid-July, serious defoliation occurred early in August, more than one month before normal leaf fall.

The relative susceptibility of poplars to $M$. populi found in the field study was identical to that found in the laboratory (Table 2). For the sake of brevity, only those species which were not tested in laboratory are presented here. In the section Tacamahaca, $P$. maximowiczii Henry and $P . \times$ woobstii (Regel) Dode were susceptible. In contrast, $P$. trichocarpa Torr. \& A. Grey was highly resistant. Among the hybrids of Tacamahaca $\times$ Aigeiros, $P . \times$ berolinensis (C. Koch) Dippel was susceptible, whereas $P . \times$ generosa Henry was highly resistant. There was no difference in susceptibility to $M$. populi between young trees and adult trees in the same poplar species.

During the field study, the leaf samples of $P$. alba 'Nivea' with typical symptoms induced by $M$. castagnei were collected. The leaf-disc inoculation method (mentioned before) was employed to determine the susceptibility of several poplar species to this fungus.

In the section Populus, P. alba and P. alba 'Nivea' were highly susceptible, whereas only one acervulus formed on each of 4 out of 8 leaf-discs of $P$. tremula. In the section Aigeiros, $P$. nigra was highly resistant. In the section Tacamahaca, $P$. koreana was more 
Table 2. Susceptibility of Populus to Marssonina species following inoculation on both leaf surfaces with conidial suspension (5000 or 20000 conidia per disc).

\begin{tabular}{|c|c|c|c|c|c|c|}
\hline \multirow{4}{*}{$\begin{array}{c}\text { Host } \\
\text { Species, hybrid, or cultivar }\end{array}$} & \multicolumn{6}{|c|}{ Susceptibility to Marssonina } \\
\hline & \multirow{2}{*}{\multicolumn{2}{|c|}{$\begin{array}{c}\text { M. populi } \\
5000 / \text { disc. }\end{array}$}} & \multicolumn{4}{|c|}{ M. castagnei } \\
\hline & & & \multicolumn{2}{|c|}{$5000 /$ disc. } & \multicolumn{2}{|c|}{$20000 /$ disc } \\
\hline & & $\mathrm{AB}$ & $\mathrm{AD}$ & $\mathrm{AB}$ & & $\mathrm{AB}$ \\
\hline \multicolumn{7}{|l|}{ Section Populus (Leuce) } \\
\hline P. alba $\mathrm{L}$. & $0^{2)}$ & 0 & & & 3 & 2 \\
\hline P. alba 'Nivea' & & & 2 & 3 & 3 & 3 \\
\hline P. tremula ssp. davidiana (Dode) Worosch. & 0 & 0 & & & & \\
\hline P. tremula L. & 0 & 0 & & & 0.5 & 0.5 \\
\hline P. tremuloides Michx. & 0 & 0 & & & & \\
\hline P. tremula $\times$ tremuloides & 0 & 0 & & & 0 & 0 \\
\hline \multicolumn{7}{|l|}{ Section Aigeiros } \\
\hline P. nigra L. & 3.5 & 3.5 & & & 0 & 0 \\
\hline \multicolumn{7}{|l|}{ Section Tacamahaca } \\
\hline P. balsamifera $\mathrm{L}$. & 1 & 2.5 & & & & \\
\hline P. balsamifera L. 'Elongata' & 0 & 1 & & & 0 & 0 \\
\hline P. balsamifera $\times$ trichocarpa Torr. \& A. Gray ex Hook. & 0 & 1 & & & & \\
\hline P. koreana Rehd. & 2 & 3 & & & 0.5 & 2 \\
\hline P. laurifolia Lebed. & 1 & 2 & & & & \\
\hline$P . \times$ rasumowskiana $($ Regel) Dippel & 3.5 & 3.5 & & & 1 & 0 \\
\hline \multicolumn{7}{|l|}{ Sect. Aigeiros $\mathrm{x}$ sect. Tacamahaca } \\
\hline$P$. 'Geneva' & 1 & 2 & & & & \\
\hline P. $\times$ petrowskiana (Regel) Schneid. & 2 & 3 & & & & \\
\hline
\end{tabular}

1) $\mathrm{AD}=$ adaxial, $\mathrm{AB}=$ abaxial

2) Mean disease rating of 8 leaf-discs

susceptible than $P . \times$ rasumowskiana (Table 2). In the field, slight premature defoliation on $P$. alba 'Nivea' caused by $\boldsymbol{M}$. castagnei was observed at the end of August.

The development of the disease under controlled conditions

Under the conditions in this study, the incubation period lasted from 4 to 5 days. Some whitish grey acervuli developed on the surface of the leaves 8 days following inoculation, a large number of acervuli formed and symptoms remained at this level until Day 12 from inoculation. The average disease class was
3.5. Thereafter, infected leaves began to fall; and $50 \%$ of the foliage had fallen by Day 20 from inoculation. The controls were free from infection. The results revealed that the disease developed rapidly and induced serious damage on $P . \times$ rasumowskiana under favorable condition.

\section{Discussion}

The leaf-disc inoculations of various poplars with a conidial suspension of $M$. populi showed results consistent with those found in the field. On P. x rasumowskiana, the same level of infection was obtained in the field as in the growth chamber inocu- 
lations. These results suggested that 5000 conidia per leaf-disc $(2 \mathrm{~cm}$ diam.) was a suitable inoculum level.

The observations in this study agreed with those of Gremmen (1964, 1965) and Spiers (1984): $M$. populi was pathogenic only to species of the section Aigeiros, Tacamahaca, and Aigeiros × Tacamahaca. Although many species, hybrids, and cultivars in these two sections could be infected, only $P$. nigra and $P . \times$ rasumowskiana were seriously damaged. In view of the limited distribution of those poplars, $M$. populi was not considered as an economically important pathogen in Finland.

In the section Tacamahaca and in the hybrids of Aigeiros $\times$ Tacamahaca, except for P. $\times$ rasumowskiana, there were marked differences in susceptibility on the leaf surface, with the abaxial surface being more susceptible to infection of $M$. populi. This phenomenon has also been found in several species, cultivars, and hybrids in the same sections (Spiers 1984). The mechanism of infection was not studied.

In the field, only P. alba and P. alba 'Nivea' were found to be infected by $M$. castagnei. However, in the laboratory inoculations, $P$. koreana in the section Tamahaca was also susceptible. This was in agreement with the results obtained by Spiers (1984), except that the fungus caused also slight symptoms on the leaf-discs of $P$. tremula. It was not studied whether $M$. castagnei infects $P$. tremula at the lower level of inoculum.

Conidial septation has been used to differentiate between $M$. populi and $M$. castagnei (Gremmen 1965). In this investigation, conidia of $M$. populi and $M$. castagnei from several poplar species used in the leaf-disc inoculations or collected in the field were measured. The dimensions of the conidia varied considerably, but the septum location was generally stable: the average length of the smaller cells of conidia was c. $30 \%$ of average total length in M. populi, and c. $40 \%$ in $M$. castagnei. During the present study, the perfect stage of $M$. castagnei was not found. Considering the life cycle of $M$. populi, the perfect stage could be found also in Finland.

$M$. brunnea, the economically most important Marssonina species on poplars, was not found in this study. A previous report of $P$. tremula infected by $M$. populi in Finland (Buchwald et al. 1961) was not verified. The species in the earlier report could have been $M$. brunnea f. sp. trepidae according to Spiers' (1984) classification, in which the fungi on $P$. tremula $\mathrm{L}$. and $P$. tremuloides Michx. were given this designation.

Acknowledgements. The senior author thanks the staffs of the section of Forest Pathology for their kindness and the facilities made available to him while he was a visiting scholar at the Finnish Forest Research Institute. The English tcxt was edited by Ms. D. Ruuskanen.

\section{References}

Anonymous 1981: Les maladies des peupliers, Groupe de Travail des Maladies de la Commission Intemationale du Peuplier, - pp. 103-137. Champagne-sur-Seine, France.

Anonymous 1979: Poplar and willow. - 328 pp. Rome.

Buchwald, N.F., Kujala, V., Roll-Hansen, F., Björkman, E. \& Käärik, A. 1961: Lists of parasitical fungi and of hosts of such fungi. - Medd. norske skogforsøksv. 17:1-36.

Gremmen, J. 1964: The Marssonina disease of poplar. (2) Inoculation experiments on leaf discs with ascospores and conidia. - Nederl. Bosb. Tijdschr. 36:149-157.

Gremmen, J. 1965: Three poplar-inhabiting Drepanopeziza species and their life-h. story. - Nova Hedwigia 9:170176.

Kam, M. de 1975: Ascospore discharge in Drepanopeziza punctiformis in relation to infection of some poplar clones. - Eur. J. For. Patho'. 5:304-309.

Karhu, N. 1986: Helsingin poppulit. - 130 pp. Helsinki.

Rimpau, R.H. 1962: Untersuchungen über die Gattung
Drepanopeziza (Kleb.) v. Höhn. - Phytopath. Z. 43: 257-306.

Semb, L. \& Hirvonen-Semb, A. 1964: Parasitic fungi on leaves of Populus. - Årsslerift planteskoledr. dendrol. 11:24-39.

Spiers, A.G. 1978: An agar leaf-disc technique for screcning poplars for resistance to Marssonina. - Plant Discase Reporter 62:144-147.

Spiers, A.G. 1983: Host range and pathogenicity studies of Marssonina brunnea to poplars. - Eur. J. For. Pathol. 13:181-196.

Spiers, A.G. 1984: Comparative studies of host specificity and symptoms exhibited by poplars infected with Marssonina brunnea, Marssonina castagnei and Marssonina populi. - Eur. J. For. Pathol. 14:202-218.

Spiers, A.G. \& Hopcroft, D.H. 1984: Influence of lcaf age, leaf surface and frequency of stomata on the susceptibility of poplar cultivars to Marssonina brunnea. - Eur. J. For. Pathol. 14:270-282. 